\title{
EL EXILIO COMPARTIDO. COMIDA, ARTE Y NOSTALGIA
}

\author{
Javier Leñador González-Páez
}

Universidad de Sevilla. jlenador@us.es

\begin{abstract}
This paper pursues to highlight nostalgia's capacities that may contribute to experience different feelings, e.g., social attachments and empathy. Considering nostalgia as an emotion that may be trigger by sensorial stimuli, such as those coming from the olfactory and gustatory senses, food might be a great booster for nostalgia. That way, gustatory experiences may be richer, shared and even reflective mediated by nostalgia feelings. Hence, the paper will focus on those expositive oeuvres that ask for the participation of the public not only visually but gustatorily, making the taste its central concern. Only when the position of taste in the museum is explained and the processes involved in nostalgia analyse will we concentrate on our main purpose: to associate nostalgia's psychological potentialities with gustatory oeuvres in order to make their political statement stronger.
\end{abstract}

Keywords: nostalgia, Proust effect, gustatory art, critical art, food.

Resumen: Con el presente título queremos hacer referencia a las capacidades socializadoras y empáticas que la nostalgia puede procurar al sintiente. Si entendemos la nostalgia como una emoción que puede ser activada por estímulos sensitivos entre los que se encuentra el gusto y el olfato, la comida puede ser un gran impulsor nostálgico, lo que podría hacer la experiencia gustativa todavía más rica, compartida y, como veremos, hasta reflexiva. El trabajo centra su análisis en aquellas obras museísticas -las que circulan dentro del circuito expositivo de las bellas artes- que involucran al público no solo visualmente, sino a través del gusto, convirtiéndolo en elemento central de su experiencia y su mensaje crítico. Tras ver el papel del gusto en el museo y explicar la experiencia y los procesos orgánicos de la nostalgia, nuestro objetivo será el de vincular las potencialidades psicológicas de la nostalgia (socialización, reducción de prejuicios, fomento de la inspiración, etc.) con dichas obras gustativas bajo la premisa que la experimentación nostalgica puede mejorar la eficacia política y crítica de tales obras.

Palabras clave: nostalgia, efecto Proust, arte gustativo, arte crítico, comida.

Citar como: Leñador González-Páez, J. (2022). "El exilio compartido. Comida, arte y nostalgia". En: Actas del III Congreso Internacional sobre Patrimonio Alimentario y Museos. 25-26 noviembre, 2021, Valencia, España. pp. 205-215. https://doi.org/10.4995/EGEM2021.2021.13929 


\section{El gusto: un sentido tradicionalmente alejado de la estética}

Incluso hoy día, la comida está desacralizada en el museo, confinada en una sala más o menos lustrosa llamada cafetería-restaurante. En el resto del complejo, la comida de cualquier tipo está vetada y el propio acto de comer es visto como una falta de respeto para con la institución museo, o peor, con el Arte (así en mayúsculas). Por lo general lo más que encontramos sonrepresentaciones artísticas de alimentos, siendo el caso más obvio es el de los bodegones, o en todo caso, alimentos reales utilizados con fines hápticos y sobre todo visuales, pero no gustativos, como el plátano de Cattelan - de hecho, fue noticia que alguien desafiara las reglas sociales y se lo comiera. En alguna ocasión podemos presenciar performances dondeel actuante es el único que puede comer, pero el arte que utiliza los alimentos para ser ingeridos y degustados por el público es todavía marginal a pesar de que su presencia en el mundo arte a raíz la explosión performativa, instalativa y relacional acaecida hacia la décadade los 60.

Todavía hoy, cuando se habla del gusto en la institución arte no se habla del sentido degustativo, ese que empleamos cada poco al realizar cualquier comida. Se habla del gusto entendido como discernimiento estético, que nace por metonimia del primero, y que, sin embargo, se ha llevado todo el protagonismo desde el nacimiento de la estética como cienciae incluso antes. Se ha dado entonces la paradoja de que todos los filósofos, estetas y connoisseurs han hablado del gusto al tiempo que relegaban el propio sentido del gusto a laszonas abisales de la estética.

En este sentido, Carolynn Korsmeyer (1999) atendió de manera magistral a las razones fisiológicas e históricas que han hecho separar, desde la estética y disciplinas afines, a los sentidos en dos grupos: unos de primer orden o elevados - vista y oído- y otros de segundoorden, vilipendiados -tacto, olfato y gusto. Atendiendo a razones espirituales e históricas, los sentidos de segundo orden están en contacto directo -o casi para el caso del olfato- con la materia que les procura las sensaciones, lo que los hace mucho más corpóreos. En unatradición teológica y filosófica donde el cuerpo era poco más que un continente impuro parael alma, su corporeidad llevaba a su devaluación. Además, en especial el tacto y el gusto, procuraban un placer que podían llevar al exceso - glotonería y desenfreno sexual-, lo queponía en jaque la virtud y constata una fundamentación moral. De igual forma, atendiendo ala epistemología, los sentidos elevados nos darían más información que los degradados al estar sus propiedades más categorizadas y ser más discernibles - para el caso de la vista pensemos en la cantidad de gradaciones y especificaciones que podemos realizar en torno al

color y la forma. Un sentido hacia el que también apuntan los formalistas, que no ven en los estímulos aprehendidos por los sentidos relegados una estructuración de sus cualidades; sus matices tienden a mezclarse y perderse. Finalmente, para hablar de su fundamentación cognitiva y fisiológica, que es la que parapeta a la estética como ciencia, Korsmeyer nos presenta a Kant, quien basa la apreciación estética en el requisito del desinterés. Un requisitoimposible de cumplir por el sentido del gusto en tanto responde a un interés fisiológico vital:el hambre. Además, Kant considera al olfato y el gusto como eminentemente subjetivos, donde apenas participa la razón, por lo que se relacionan con el placer personal y no puedendar lugar a juicios con visos de universalidad, otro de sus requisitos para la experiencia estética. Fue eso lo que lo llevó a dividir los gozos procurados por los sentidos bajo dos categorías diferenciadas: lo bello y lo estético para los sentidos elevados y lo meramente placentero y agradable para los minusvalorados. 
Pero a nuestro juicio, estas fundamentaciones, aunque sensatas y dialécticas, no dejarían de responder a cuestiones superiores que han sido ya apuntadas por Pierre Bourdieu. Este considera que la visión kantiana del desinterés y otros requisitos estéticos similares serían fruto de una construcción histórica fundada por aquellos que tenían el suficiente tiempo librepara la contemplación desinteresada y ostentaban una posición de poder en el entramado social que les permitía imponer su criterio teleológico y estético. Dicho de otro modo, la jerarquía de las artes y su valor estético se correspondería con la jerarquía de los consumidores, lo que hace que los gustos funcionen como marcadores de clase y que la separación entre sentidos estéticos y no estéticos se base en cuestiones sociales, religiosas ymorales y no naturales, posteriormente universalizados a través de la educación (Bourdieu, 1984).

\section{La nostalgia como emoción y como experiencia}

La nostalgia se puede definir brevemente como una emoción de carácter ambivalente en la que se entremezcla placer y dolor al recordar un evento pasado. Aunque la emoción nace conla propia cultura, el término como tal no aparece hasta el 22 de junio en 1688 en el campo médico, cuando Johannes Hofer la acuña en su tesina titulada Dissertatio medica de nostalgia oder Heimweh. Su etimología responde a la unión de dos vocablos griegos: nostos (retorno,a la patria según Hofer) y algios (dolor o tristeza). Así, en un principio, la nostalgia tuvo unaconnotación negativa, pues se consideraba una enfermedad que Hofer identificaba en los soldados suizos movilizados a otras latitudes del continente europeo, presentándose como una turbación de la imaginación en la que solo se contemplaba el regreso a la patria y que solía llevar a la acedia o estados depresivos, propiciando, en algunos casos, la muerte del enfermo (Hofer, 1992). Así, si bien es cierto que los orígenes arrojan una visión negativa y una referencia al espacio geográfico, con los años el término se irá transformando, virando hacia una consideración neutra o positiva y trasladándose al espacio temporal. Ya no se habladel regreso -imaginado- a la patria, sino a un tiempo pasado.

Hoy día, la nostalgia se considera un concepto en auge, en especial en la esfera social, pues culturalmente vivimos más que nunca en un mundo fuertemente nostálgico, donde el pasado ocupa un papel relevante y las creaciones culturales y mercantiles que llaman a la nostalgia son numerosas. De hecho, Bauman considera que no encontramos en "la era de la nostalgia" (Bauman, 2017), palabras que entendemos suficientes para justificar el tema de nuestro trabajo.

Pero nuestro interés no se centra en la esfera social, sino en la individual, en la emocional y experiencial de la nostalgia. Y aquí, uno de los primeros grandes analistas no lo encontramosen la psicología o en campos afines, sino en la literatura, en la figura de Marcel Proust, cuyaobra ecuménica En busca del tiempo perdido (1913-1927) se construye temática y compositivamente en torno a la nostalgia. En ella se analiza una experiencia evocadora concreta que ha trascendido a la posteridad: ese momento en el que el protagonista se lleva una magdalena a la boca y una fuerte emoción lo embarga, llevándolo a rememorar recuerdos de su infancia en Combray. Es esta experiencia concreta la que nos hará de guía a la hora deexplicar algo más en profundidad la fenomenología de la nostalgia.

\section{1 ¿Qué le ocurrió a Proust al morder su magdalena? La experiencia nostálgica explicada}

[...] Abrumado por el triste día que había pasado y por la perspectiva de otro tan melancólico por venir, me llevé a los labios una cucharada de té en el que había echado un trozo de magdalena. Pero en el mismo instante en que aquel trago, con las migas del bollo, tocó mi paladar, me estremecí, fija mi atención en 
algo extraordinario que ocurría en mi interior. Un placer delicioso me invadió, me aisló, sin noción de lo que le causaba. Y él me convirtió las vicisitudes de la vida en indiferentes, sus desastres en inofensivos y su brevedad en ilusoria, todo del mismo modo que opera el amor, llenándose de una esencia preciosa; pero, mejor dicho, esa esencia no es que estuviera en mí, es que era yo mismo. Dejé de sentirme mediocre contingente y mortal. ¿De dónde podría venirme aquella alegría tan fuerte? Me daba cuenta de que iba unida al sabor del té y del bollo, pero le excedía en mucho, y no debía de ser de la misma naturaleza. ¿De dónde venía y qué significaba? ¿Cómo llegar a aprehenderlo? Bebo un segundo trago, que no me duce más que el primero; luego un tercero, que ya me dice un poco menos. Ya es hora de pararse, parece que la virtud del brebaje va aminorándose. Ya se ve claro que la verdad que yo busco no está en él, sino en mí. El brebaje la despertó, pero no sabe cuál es y lo único que puede hacer es repetir indefinidamente, pero cada vez con menor intensidad, ese testimonio que no sé interpretar y que quiero volver a pedirle dentro de un instante y encontrar intacto a mi disposición para llegar a una aclaración decisiva. Dejo la taza y vuelvo hacia mi alma. [...] Y de pronto el recuerdo surge. Ese sabor es el que tenía el pedazo de magdalena que mi tía Leoncia me ofrecía, después de mojado en su infusión de té o de tila, los domingos por la mañana en Combray [...]. Ver la magdalena no me había recordado nada, antes de que la probara; quizá porque, como había visto muchas, sin comerlas, en las pastelerías, su imagen se había separado de aquellos días de Combray para enlazarse a otros más recientes; iquizá porque de esos recuerdos por tanto tiempo abandonados fuera de la memoria, no sobrevive nada y todo se va disgregando! [...] Combray entero y sus alrededores, todo eso, pueblo y jardines, que va tomando forma y consistencia, sale de mi taza de té. (Proust, 2016, pp. 66-71)

Esta verdadera re-vivencia de una experiencia pasada es lo que Proust llamó moments bienheureux (momentos dichosos) (Epstein, 2004), escenas que creemos que quedan esencializadas a la perfección en los extractos recién enunciados como intensas, emotivas, frugales, vitales, trascendentes, evocadoras. Momentos que han sido reproducidos ampliamente en multitud de obras literarias y cinematográficas, como en Ratatouille, cuandoel crítico gastronómico Anton Ego recuerda su infancia al probar el plato que Remy le ha preparado o en Una receta familiar, película singapurense basada en la relacional emocionaly familiar con la cocina. También se pueden leer en obras literarias mucho más recientes quela de Proust, como Aromas, de Philippe Claudel, o El dios de las pequeñas cosas, de Arundhati Roy; e incluso ha sido utilizado con fines mercantilistas en campañas de publicidad, como la de cocinas Teka.

Indudablemente, el poder de la imaginación y la memoria son esenciales en tales experiencias evocadoras como las de la magdalena. Concretamente, participa el tipo de memoria que se conoce como episódica, que guarda información respecto a eventos o episodios temporales y sus relaciones espacio-temporales y siempre toma un sentido autobiográfico. Todo dentro de un desarrollo totalizador e indiferenciado que involucra a la memoria semántica, el otro tipo de memoria que guarda información cognitiva y no perceptiva, como símbolos y datos y su relación (Tulving, 1972).

Si profundizamos en el proceso de rememoración que se encuentra en esos momentos felices, Proust se refiere de manera tácita a la memoria involuntaria. Al contrario de la memoria voluntaria, que es un proceso donde se recupera información adrede, la involuntaria trae los recuerdos a la conciencia con aparente espontaneidad, sin pretenderlo (Berntsen, 1996). De hecho, Proust nos dice en el texto referenciado que el "recuerdo surge" (Proust, 2016) como si fuera de manera espontánea, sin su propia voluntad. El literato es consciente de esta diferencia capital, y es que, en el mismo volumen de su obra, Proust nos habla de la memoria voluntaria en sentido peyorativo -al menos para la generación de imágenes emocionalmente atractivas: "Pero como lo que yo habría recordado de eso serían cosas venidas por la memoria voluntaria, la memoria de la inteligencia, y los datos que ella da respecto al pasado no conservan de él nada, nunca tuve ganas de pensar en todo lo demás de Combray" (Proust, 2016, p. 66). Y es que parece que esta 
es una verdad generalizable, pues estudios científicos demuestran que el recuerdo involuntario, frente al voluntario, permite la recuperación de más episodios concretos y mayores respuestas emocionales y corporales en tanto activa en mayor medida la memoria episódica específica, asociados con mayores dosis de revivencia y emocionalidad (Berntsen y Hall, 2004).

Ahora bien, ¿cómo podemos explicar la transición o el juego de la imaginación que posibilita el gozo presente en base a un recuerdo? ¿Cómo transita nuestra mente de la magdalena que comemos hoy a la que comimos muchos años atrás en nuestra infancia?

Para explicarlo recurriremos a la teoría de Russell Epstein (2004), que hace uso del concepto de fringe contextual information con el que William James explica el paso de un momento de consciencia a otro. Esta información contextual o marginal a la que James alude es aquellaque rodea a la información sensitiva más sobresaliente o nucleus en una experiencia dada -en este caso, las experiencias sensitivas más notorias de la magdalena en el presente, como su sabor- y está formada por tres componentes: una débil memoria de pensamientos y sensaciones precedentes, un entendimiento de la relación entre el actual pensamiento focal ylas sensaciones u otros pensamientos que puedan ser relevantes y un sentimiento hacia el queel objetivo de nuestra consciencia se dirige. Normalmente solo nos percatamos del núcleo sensitivo, pero en ocasiones esta información relacional se nos hace consciente gracias a la memoria involuntaria. Esta memoria es la única capaz de traer la información contextual deun evento y la red de asociaciones que involucra, pues es una información que no había sidoracionalizada y la hace ahora consciente, haciendo que las sensaciones tengan una presenciaemocional tan viva como las presentes y nucleares. Todo esto es posible gracias a la labor del hipocampo, pues una vez este ha recibido un estímulo de los sentidos lo completa con elementos que estaban asociados con otros estímulos que seguían el mismo modelo en el pasado. La información es posteriormente transmitida al córtex, donde se evoca un nuevo pensamiento conscientemente experimentado, una imagen mental capaz de emocionarnos (Epstein, 2004).

Hasta ahora no hemos hablado más que del proceso en sí y hemos hecho mención a estímulos de manera general, pero, ¿ese proceso puede variar en función del tipo de estímulo que lo active? La realidad es que ese fuerte impacto nostálgico puede venir de un estímulo visual o sonoro, como habremos sentido muchos de nosotros, e incluso del propio juego de la mente, de forma endógena. Sin embargo, tanto Proust como la ciencia concuerdan en que son precisamente los estímulos percibidos por esos órganos de segundo orden los que más capacidad evocadora tienen. En el propio extracto, Proust nos dice que el estímulo visual de la magdalena no le causó tal experiencia aduciendo a una suerte de sobreestimulación visual. Es decir, había visto tantas magdalenas antes que la asociación con las pretéritas magdalenas de Combray se había borrado. Esto puede hacernos llegar a la conclusión de que mientras menos repetido sea el estímulo, más probables son los moments bienheureux. Tendría sentido entonces que sentidos no tan sobreestimulados como olfato y gusto, así como los estímulos que no se han hecho cotidianos, sean más efectivos en la formación de experiencias intensamente nostálgicas. Y esto lo ratifica la ciencia en tanto queda demostrado que los olores -es por todos sabido el importante papel que el olfato tiene en la propia experiencia gustativa- recuperan recuerdos más emocionales que los estímulos visuales y verbales y que aún son más evocadores cuanto más distintivos y novedosos son (Herz y Schooler, 2002). Esto se debe a que los activadores olfativos excitan más la amígdala de lo que lo hacen los auditivos o visuales y se asocian de forma más directa con el lobo temporal y límbico, la región más "emocional" del cerebro y allí 
donde se encuentra el hipocampo, encargado del procesamiento positivo de la memoria (Reid et al., 2015). De igual manera, se ha confirmado que los activadores olfativos son más efectivos que los visuales trayendo memorias de la infancia al presente. Por tanto, los olores son mejores evocadores de eventos que ocurrieron mucho tiempo atrás (Bruijn y Bender, 2018), lo que nos llevaría a una diferenciación de activadores según el órgano receptor-distancia del recuerdo que corre en el mismo sentido que nuestra hipótesis sobre la sobreestimulación.

Creemos que todos estos estudios sobre el olfato se pueden extrapolar al sentido del gusto dada la ya comentada dependencia entre ambos. Además, en la propia experiencia culinaria se ven involucrados todos los sentidos, tanto los más obvios, como el olfato y el tacto -este último es el que permite apreciar las diferentes texturas de los alimentos en la boca- comola vista y el oído al valorar la apariencia visual de los alimentos y el sonido que estos puedenhacer al quebrarse o al morderlos y que nos pueden ayudar a valorar algunas de sus cualidades, como el punto de cocción o la frescura. Realmente, la experiencia culinaria en condiciones normativas es sensiblemente totalizadora.

\section{1 ¿Podemos hablar de una experiencia estética?}

Estos moments bienheureux o agudamente nostálgicos creemos que cumplen con la caracterización de las experiencias -el concepto de An Experience- que Dewey define como un suceso experimentado subjetivamente con unidad propia, donde se mezcla lo intelectual con lo emocional de manera indiscernible y que es en sí misma conclusiva. Deweyda a esas experiencias la cualidad de estéticas, una estética basada no en los materiales - como las obras de arte visuales-, sino por medio de esa integración conclusiva per se gratificante (Dewey, 2005). Es esta la idea de partida que los estetas de los cotidiano como Thomas Leddy (2012) y Yuriko Saito (2007) utilizan para fundamentar sus teorías y que bienpodrían servir para otorgar a experiencias sensitivas como las culinarias el estatus deexperiencias estéticas, desoyendo las teorías kantianas y poskantianas. En realidad, una ideasimilar fundamenta la concepción artística que Proust tenía de su obra. Lo que hace el escritor, según Epstein, al describir sucesos como el de la magdalena -en realidad hay otros similares a lo largo del libro- es crear una suerte de metáforas que funcionan como digresiones que brotan de la narrativa principal para eludirla momentáneamente y que emulanel proceso que supone vivir esos momentos dichosos que nos hacen olvidar el presente. De esta manera, lo que Proust persigue es capturar la esencia de las cosas, es decir, una estructura estable de memorias y conocimiento que él creía que existía fuera del tiempofenomenológicamente experimentado, esto es, de manera secuencial. Esto se conseguiría solo de dos formas, a través de la memoria involuntaria y el arte. El primero ayuda a crear elfenómeno directamente en la mente con cualquier objeto; el segundo lo hace "ficticiamente" al presentar al observador con una serie de recursos o topos/símbolos que crean una red de asociaciones (Epstein, 2004). Como vemos, una concepción muy similar a la de las experiencias de Dewey y que refuerza la posibilidad de abrir una vía propia para suvaloración estética.

\section{Hacia una teoría de la nostalgia en el arte: el aprovechamiento de sus beneficios psicológicos en la dimensión crítica de las obras de arte}

Una vez apuntado el valor estético de las experiencias nostálgicas, nuestra labor ahora será traer a escena estudios recientes en el campo de la psicología que caracterizan la nostalgia como una emoción eminentemente positiva y proactiva. Contradiciendo lo que antes era supuesto, la 
nostalgia está lejos de provocar un estado comparable a la ataraxia o el puro sentimentalismo, sino que se erige como una emoción compensatoria y orientada hacia el futuro que promueve la actividad (Wildschut et al., 2006; FioRito y Routledge, 2020). Es precisamente por ello que creemos en la experiencia estética de la nostalgia como un arma para la acción -mental o física- que podría llevar incluso a potenciar la dimensiones críticas, morales y políticas de las obras de arte.

La primera consecuencia positiva de la nostalgia es el incremento de la socialización o de la interacción social. La nostalgia es social en un doble sentido: en sus contenidos y en su alcance. En cuanto a lo primero, la mayoría de los recuerdos nostálgicos rememoran un evento rodeado de nuestros amigos y familiares. Un estudio realizado por Wildschut y sus compañeros revela que los objetos de rememoración más repetidos durante un sentimiento de nostalgia fueron las personas (33\%), seguido de los eventos (28\%), los cuales solían ser grupales. De este modo, el acceso a estructuras relacionales positivas previas lleva a una suerte de optimismo a la hora de crear o fortalecer lazos sociales (Wildschut et al., 2006). Encuanto a su alcance, estudios recientes concluyen que las experiencias nostálgicas tienden a compartirse (FioRito y Routledge, 2020), de modo que sería una herramienta valiosa para entablar conversaciones e intercambiar pareceres, pudiendo dar lugar a debates sobre la eficacia política de la obra o sobre las vicisitudes morales del asunto que es puesto de relievepor la obra. Y no solo eso, sino que además pueda ayudar a reducir los prejuicios para con la gente con la que el individuo está interactuando. Esta reducción sigue las lógicas relacionadas con la interacción social, pero siendo mediada por la empatía y estando condicionada por lacualidad de los recuerdos rememorados. Es habitual que los recuerdos evoquen ternura, caloro familiaridad invocando a personas significativas de nuestro pasado, por lo que gracias a laempatía, estas cualidades sean trasladadas al grupo externo, reduciendo los prejuicios que pudieran sentir hacia ellos y siendo más proclives a establecer un acercamiento (Sedikides y Wildschut, 2019).

El segundo beneficio que merece la pena señalar es el de la potenciación de la inspiración. Estudios psicológicos señalan que la nostalgia fortalece distintos recursos psicológicos, comola señalada conectividad social y la autoestima, lo que lleva a que los individuos sean más proclives a proyectar nuevas ideas y nuevos planes (Stephan et al., 2015). Esto creemos quees fundamental para que la obra trascienda, para que los individuos afectados emocionalmente por la obra no solo se vean informados de una determinada situación o se queden en un primer estadio presidido por la indignación, la rabia o la pesadumbre. Graciasa la nostalgia, las probabilidades de ser reactivos e incluso tomar acción a favor de la causa se ven incrementadas. De hecho, estudios demuestran que aquellos afectados nostálgicamente son más proclives a donar tiempo y dinero para determinada causa, es decir,se muestran más caritativos gracias a la mediación de la empatía promovida por la nostalgia(Zhou et al., 2012).

Relacionado con este último encontramos la estimulación de la creatividad y que supondría la materialización del punto antes señalado. La nostalgia puede llevar a crear obras de arte, asociaciones, empresas, escritos, etc., siguiendo la lógica señalada por Stephan y sus compañeras, acoplándose el incremento del optimismo comentado por Cheung (Cheung et al., 2016). Este optimismo se relaciona con la adopción de opciones con más riesgos, menosconservadoras, lo que se proyecta en una apertura de miras que puede beneficiar a la creatividad al fomentar un pensamiento más flexible que incluye distintas categorías cognitivas, cambio de aproximaciones y el uso de asociaciones lejanas (van Tilburg et al., 2015). 
Podemos entonces concluir con la idea demostrada de que los efectos de la nostalgia sobre nuestro cuerpo y nuestra mente son positivos y movilizadores a pesar de poder verse acompañados de alguna nota negativa o agridulce asociadas eminentemente por la pérdida de lo rememorado (Sedikides y Wildschut, 2019). Beneficios sociales como el incremento de la interacción social, la reducción de prejuicios, la caridad o la inspiración cambiarán el modo en el que vemos nuestro entorno, haciéndonos más proclives a la movilización políticay social. Indudablemente, también ha de hallarse una predisposición de tipo racional y moralpara llevarla a cabo, pero la nostalgia puede dar ese paso que de otro modo nunca daríamos,haciendo de la obra de arte una herramienta más efectiva en la consecución de sus fines políticos o sociales.

En este mismo sentido, también creemos que la entrada en un museo nos puede hacer estar más activos cognitivamente, pues esperamos que algunas obras -especialmente en museos contemporáneos - demanden cierto esfuerzo cognitivo. Esta predisposición es lo que creemos que puede hacer trascender la experiencia nostálgica más allá de un primer estado puramente sensible y que se relaciona directamente con los tres órdenes ascendentes de la nostalgia sistematizados por Fred Davis. La nostalgia de primer orden o simple se trataría poco más de una sentimentalización del pasado, mientras que la de segundo orden o reflexivasería cuestionarse el porqué de esa sentimentalización, preguntarse si realmente ese pasado era tan bello o si, a pesar de esa nostalgia, seguimos prefiriendo el presente. La nostalgia detercer orden o interpretada es la que creemos que puede potenciarse en un museo por las causas aludidas, y se trataría de un análisis fenomenológico que nos llevaría a plantearnos elpropio proceso nostálgico (Davis, 1979). En este último nivel se daría cabida a cuestiones detipo moral y político tales como: ¿es legítima o recomendable esta experiencia en estas circunstancias? ¿supone mi nostalgia, mi sentimiento placentero, una desconsideración haciaotros agentes implicados directa o indirectamente en la obra? Serían este tipo de preguntas las que podrían hacer considerar al individuo cuestiones políticas y éticas a partir de la nostalgia desde un polo cognitivo, lo que, unido a los propios beneficios psicológicos directosde la emoción, podrían potenciar el cuestionamiento de la realidad social y la toma de partido.

Intentemos ahora trasladar estas ideas tres a ejemplos concretos de obras museísticas.

La primera obra que traemos se titula Padded Cell y fue realizada por Jennifer Rubell en 2011 para el evento Performa Arts' Red Party en Nueva York. Se trataba de una caja- habitación espartana de 2,5 x 5 metros que contaba únicamente con una puerta y una bombilla; la sorpresa se encontraba en sus paredes y techo, recubiertos enteramente por 1600 ladrillitos de algodón de azúcar (Yoneda, 2011). De este modo, al visitante se le daba la oportunidad de entrar e ir destruyendo la cubrición de la habitación al ir comiéndose algodón de azúcar, un dulce que con facilidad puede evocar a nuestra infancia. Sin embargo, bajo estaestética de estímulos apacibles se escondía una crítica ya desde el propio nombre de la obra,que hace referencia a las salas de aislamiento acolchadas que se podían ver con frecuencia en los psiquiátricos. Esta referencia explícita y las sensaciones claustrofóbicas que se podíangenerar en los espectadores podían potenciar la dimensión política de la obra, a la que la propia artista alude al hablar del "lado oculto del placer, su precio, y la posibilidad de dar a ese placer su propio castigo", lo que creemos que revierte en una crítica a la sociedad hedonista, donde el placer se busca maníaca, compulsivamente.

El segundo ejemplo es, sin duda, el más popular. Se trata de la obra Untitled (pad thai), realizada por Rirkrit Tiravanija por primera vez en 1990 en la galería Paula Allen de Nueva York 
y posteriormente reescenificada en otras localizaciones, algunas de gran prestigio, como el MoMA. Este happening cumbre del arte relacional pretendía, ante todo, crear comunidad, pero también tenía una visión crítica que el propio artista reconoce en una entrevista al aludir de manera indirecta al colonialismo y al nacionalismo identificado en la comida (Yao, 2019). Y es que en el pad thai fue, según cuenta la historia popular, un invento de un general que quería crear un plato que fuera identificado como genuinamente tailandés, algo que logró añadiendo a los fideos chinos elementos típicos de la identidad nacional tailandesa como los cacahuetes, el chili y el tamarindo. La acción fue sencilla, cocinar, servir y comer pad thai para todo aquel que pasara por la galería y quisiera participar. Como Tiravanija reconoce (Yao, 2019), el pad thai en aquel momento estaba iniciando su internacionalización, por lo que aún era un producto exótico, lo que puede ser un potenciador o un inhibidor de la nostalgia según lo antes expuesto. Si el plato suponía una sensación totalmente nueva, que no estaba almacenada en la memoria, sería poco probable que resultara en una experiencia nostálgica. Sin embargo, si no era una comida habitual, sino que solo había sido probado en otro lugar - por ejemplo, en un viaje a Tailandia- o se había comido algo muy similar, con ingredientes similares, las probabilidades de encender el recuerdo emocional aumentarían. Lo que resulta de nuestra teoría y de los estudios psicológicos es que, de darse una emoción nostálgica en el receptor, la socialización ya facilitada por la obra se vería favorecida, los prejuicios para con la cultura tailandesa disminuidos, la empatía para con el artista tailandés y su condición de extranjera potenciada e incluso la dimensión crítica implícita revelada.

El tercer y último ejemplo que traemos in extenso se trata de Enemy Kitchen, un proyecto iniciado por Michael Rakowitz en 2003 y todavía en activo. El proyecto se basa en enseñar,cocinar y dar a probar a los viandantes comida típica iraquí desde un camión. La obra trasciende con mucho los límites de la galería, pues involucra a distintos colectivos alejadosdel mundo del arte contemporáneo, como chefs iraquíes o menores en riesgo de exclusión social. Sin embargo, la obra fue concebida por el propio artista como un proyecto artístico, siendo la cocina no un fin en sí mismo, sino un medio para la consecución de otros que teníanque ver con dar a conocer la comida iraquí y, sobre todo, desestigmatizar su cultura y a sus ciudadanos. Para entenderlo debemos valorar el contexto en el que se gestó la obra, en el quelas tropas americanas ocupaban Iraq tras la conclusión de la guerra del Golfo y se vivía una tensa crisis diplomática. Esta situación llevó a que la comunidad iraquí en Estados Unidos fuera vista con otros ojos y que ellos mismos renegaran en cierto sentido de su identidad, porejemplo, al rotular sus restaurantes tradicionales bajo la etiqueta de comida mediterránea enlugar de iraquí (Boucher, 2018). De manera similar a la obra de Tiravanija, este gran proyecto busca potenciar los lazos sociales en los encuentros, pero sobre todo disminuir las hostilidades y los prejuicios hacia una minoría como la iraquí. Creemos que la propia narrativa de la obra es ya efectiva en este sentido, pero la nostalgia, sin duda, podría potenciarla; podría ayudar a sentir ese exilio de los iraquíes, a compartirlo emocionalmente

A estas tres obras se le podrían unir muchas otras, como muchas del artista español Antoni Miralda - por ejemplo, The Seattle Banquet (1973) habla de la multiculturalidad de grandes ciudades como hemos visto indirectamente en los dos últimos ejemplos-, los famosos caramelos de González-Torres en su S/T (Para un hombre en uniforme, 1991) o algunas de las obras de artistas actuales presentes en la exposición Trapholt, Museum of Modern Art and Design en Kolding, Dinamarca. 


\section{Conclusiones}

De esta manera hemos creído no solo explicarla nostalgia, su experimentación y sus procesos, sino también cómo esta emoción, desde lo sensitivo y emocional, puede potenciar ladimensión política o crítica de la obra. Indudablemente, no podemos asegurar que la emoción esté presente tal y como no podemos pretender que la tristeza o la sublimidad de una obra sea sentida por todo el público. Nuestra capacidad de conmovernos tiene un fuerte componente aleatorio y desconocido.

Sin embargo, la ciencia apunta a que hay sentidos que pueden ser más efectivos en esa conmoción emocional. Así, el sentido del olfato y del gusto parecen ser más emocionales y evocadores que el resto, propiciando que las posibilidades de que sintamos nostalgia aumenten. Es ahí donde entra la comida como gran activador, como uno de los medios más idóneo para vivenciar experiencias estéticas hasta ahora poco consideradas en el mundo de las bellas artes.

\section{Referencias}

BAUMAN, Z. (2017). Retrotopía. Barcelona, Paidós.

BERNTSEN, D. (1996). "Involuntary autobiographical memories". Applied Cognitive Psycjology, vol. 10, pp. 435-454. https://doi.org/10.1002/(SICI)1099-0720(199610)10:5\%3C435::AIDACP408\%3E3.0.CO;2-L

BERNTSEN, D., \& HALL, N. M. (2004). "The episodic nature of involuntary autobiographical memories". Memory and Cognition, 32(5), pp. 789-803. https://doi.org/10.3758/BF03195869

BOUCHER, B (2018). 'It's a Strange Communion': Artist Michael Rakowitz on Why He Set Up an Iraqi Food Truck Outside the MCA Chicago. <https://news.artnet.com/art-world/iraq-cooking-michaelrakowitz-enemy-kitchen-1198394)> [Consulta: 22 de agosto de 2021]

BOURDIEU, P. (1984). Distinction: A social critique of the judgement of taste. Cambridge, Harvard University Press.

BRUIJN, M. J. DE, \& BENDER, M. (2018). "Olfactory cues are more effective than visual cues in experimentally triggering autobiographical memories". En: Memory, 26(4), 547-558. https://doi.org/10.1080/09658211.2017.1381744

CHEUNG, W. Y., SEDIKIDES, C., \& WILDSCHUT, T. (2016). "Induced nostalgia increases optimism (via social-connectedness and self-esteem) among individuals high, but not low, in trait nostalgia". Personality and Individual Differences, 90, 283-288. https://doi.org/10.1016/j.paid.2015.11.028

DAVIS, F. (1979). Yearning for Yesterday: A Sociology of Nostalgia. Nueva York, The Free Press.

DEWEY, J. (2005). Art as Experience. Nueva York, Perigee.

EPSTEIN, R. (2004). "Consciousness, art, and the brain: Lessons from Marcel Proust". Consciousness and Cognition, 13(2), 213-240. https://doi.org/10.1016/S1053-8100(03)00006-0

FIORITO, T. A., \& ROUTLEDGE, C. (2020). "Is Nostalgia a Past or Future-Oriented Experience? Affective, Behavioral, Social Cognitive, and Neuroscientific Evidence". Frontiers in Psychology, Vol. 11, junio, artículo 1133. https://doi.org/10.3389/fpsyg.2020.01133 
HERZ, R. S., \& SCHOOLER, J. W. (2002). "A Naturalistic Study of Autobiographical Memories Evoked by Olfactory and Visual Cues: Testing the Proustian Hypothesis". University of Illinois Press, 115(1), pp. 21-32. https://doi.org/10.1017/CB09781107415324.004

HOFER, J. (1992). "Dissertatio medica de nostalgia oder Heimweh (1688)". En: PRETE A. (Ed.), Nostalgia. Storia di un sentimento. Milán, Raffaello Cortina Editore.

KORSMEYER, C. (1999). Making Sense of Taste: Food anf Filosophy. Ithaca, Cornell University Press.

LEDDY, T. (2012). The Extraordinary in the Ordinary: the Aesthetics of Everyday Life. Buffalo, Broadview Press.

PROUST, M. (2016). En busca del tiempo perdido, 1. Por el camino de Swann. Madrid, Alianza.

REID, C. A., GREEN, J. D., WILDSCHUT, T., \& SEDIKIDES, C. (2015). "Scent-evoked nostalgia”. En: Memory, 23(2), pp. 157-166. https://doi.org/10.1080/09658211.2013.876048

SAITO, Y. (2007). Everyday Aesthetics. Oxford, Oxford University Press.

SEDIKIDES, C., \& WILDSCHUT, T. (2019). "The sociality of personal and collective nostalgia". En: European Review of Social Psychology, 30(1), pp. 123-173. https://doi.org/10.1080/10463283.20 19.1630098

STEPHAN, E., SEDIKIDES, C., WILDSCHUT, T., CHEUNG, W. Y., ROUTLEDGE, C., \& ARNDT, J. (2015). "Nostalgia-Evoked Inspiration: Mediating Mechanisms and Motivational Implications". En: Personality and Social Psychology Bulletin, 41(10), pp. 1395-1410. https://doi.org/10.1177/0146167215596985

TULVING, E. (1972). "Episodic and semantic memory". En: Tulving, E. \& Donaldson, W. (Eds.), Organization of Memory.Cambridge, Academic Press.

VAN TILBURG, W. A. P., SEDIKIDES, C., \& WILDSCHUT, T. (2015). "The mnemonic muse: Nostalgia fosters creativity through openness to experience". Journal of Experimental Social Psychology, 59, 1-7. https://doi.org/10.1016/j.jesp.2015.02.002

WILDSCHUT, T., SEDIKIDES, C., ARNDT, J., \& ROUTLEDGE, C. (2006). "Nostalgia: Content, triggers, functions". En: Journal of Personality and Social Psychology, 91(5), pp. 975-993. https://doi.org/10.1037/0022-3514.91.5.975

YAO, P (2019). The Lives of Objects: Rirkrit Tiravanija in Conversation. <https://www.mplus.org.hk/en/ magazine/the-lives-of-objects-rirkrit-tiravanija-in-conversation/> [Consulta: 22 de agosto de 2021]

YONEDA, Y (2011). Padded Cell is a Room Lined with 1,600 Cones of Cotton Candy. <https://inhabitat. com/padded-cell-is-a-room-lined-with-1600-cones-of-cotton-candy/> [Consulta: 29 de agosto de 2021]

ZHOU, X., WILDSCHUT, T., SEDIKIDES, C., SHI, K., \& FENG, C. (2012). "Nostalgia: The gift that keeps on giving". En: Journal of Consumer Research, 39(1), pp. 39-50. https://doi.org/10.1086/662199 